\title{
Evaluation of Residual Stress in the Hot Forming Process Using Hole Drilling
}

\author{
M. Jalali Azizpour ${ }^{1, a^{*}}$ and Hamed Fattahi ${ }^{2, b}$ \\ 1,2 Department of mechanics, Ahvaz Branch, Islamic Azad University, Ahvaz, Iran \\ amjalali@iauahvaz.ac.ir, 'hfattahi13@yahoo.com
}

Keywords: Hot Forming, Residual Stress, Drilling, FEM, Aluminum Alloy

\begin{abstract}
In the present study, it was attempted to perform the residual stress in the aluminum sheet A.A5083 via hot metal forming process by gas according to the Finite Element Method. The existence of the residual stress in the industrial pieces results in changing the reaction of structure against the applied load. The understanding of the effect of residual stress on the structural behavior is required and the design of the sensitive pieces regardless of the residual stress can result in financial and fatality damages. The aim of the present study was to apply an efficient approach to determine the stresses caused during the forming process with the hole drilling method. Thus, the sheet of 5083 aluminum alloy was formed by that method in an imperfect conical mold and the mentioned parameters were evaluated. At first, the section was analyzed initially and after preparing the mapping, it was modeled in the analysis software and its reliability was evaluated. The finite element analysis method of the hot metal forming process by the gas dependent on the temperature was evaluated. To simulate the forming process, ABAQUS/Explicit as the finite element software was used. At the end, the results obtained by the residual stress via the finite element method were compared with the results of the experimental tests of the piece.
\end{abstract}

\section{Introduction}

The hot metal forming process by gas blow is one of the latest methods for forming the sheet. Meanwhile, this method is considered as the most important super plastic forming methods. the hot forming by gas has been originated from super plastic forming and the hot blow forming. some of the advantages of this method against other forming methods are as follow: use in high temperatures, ability to achieve high length changes, ability to construct complicated forms made by materials, ability to increase the forming speed and reduce the cost of mould [1,2].Sorgente[3] evaluated the possibility of reducing forming time via controlling the pressure profile in a part of pieces which was under the greatest strain at the end of forming process. The hot forming is a usable method in industry that increases the formability of aluminum and magnesium. Despite this fact, this method is applied for some special alloys such as aa5083 super plastic alloy with controllable features for the hot forming [4]. the residual stress in the industrial pieces results in changing the structure reaction against the applied load thus, the recognition, determination of residual stress and evaluation of effect of residual stress on the structure behavior are necessary and the design of sensitive pieces without considering the residual stress may results in some financial and physical damages [5]. the pieces forming by the super plastic forming method has so many advantages. the forming by the super plastic forming method has so many advantages. the ability to form the pieces with complicated forms by a single mould and with no need to mandrel is one of them because the forming power is applied by gas. Some of them are: ability to form the pieces with complicated forms by a single mould and with no need to mandrel because the forming power is applied by gas. Despite that, this method has some disadvantages such as need to high temperature or power to ensure from complete forming of material inside the mould[6,7]. yu wu evaluated the properties of deformation in the thin sheet of magnesium alloy. he experimentally showed that the mean strain rate 10-2 was available and he also reported about the uniform distribution across the piece with a

(c) (1) Content from this work may be used under the terms of the Creative Commons Attribution 3.0 license. Any further distribution of this work must maintain attribution to the author(s) and the title of the work, journal citation and DOI. Published under license by Materials Research Forum LLC. 
dramatic reduction of forming time [8].meanwhile, the material behavior before applying the super plastic forming is one of the main items that must be considered because the particles size should be fine to prevent from increasing the costs of alloying and transformation processes before the recrystallization [9]. The main objective of the present study was to determine the residual stress experimentally and numerically in an imperfect cone made by gas pressure in a temperature close to melting temperature of AA5083 aluminum sheet and also the distribution of sheet thickness after the forming process.

\section{The hot metal forming by gas blow}

In the hot metal forming by the gas or the fast plastic forming, the aluminum sheet is heated to the forming temperature $\left(400-510^{\circ} \mathrm{C}\right)$. The heated sheet is put between two molds (steel or ceramic) manufactured by the sheet itself and then it is dragged to the forming tool by the air or gas pressures (nitrogen or argon) in the dorsal surface of the sheet. The forming pressure in one controlled method is constantly increased from the ambient pressure to the ultimate pressure of forming in the range of 17-34 bars or higher.

During the first several seconds to the first minute, as the pressure raises, the sheet matches itself with the tool level. In order to begin the stretching of sheet after the first period of pressuring, the pressure is raised faster. With regard to the size and the complexity of forming bodies, the forming usually is completed in 2 to 12 minutes that is considerably faster than the super plastic forming.

\section{Finite element model for sheet forming}

The shell elements are the sheets in the space and they have no shear or flexural stiffness matrix. Thus, only the non-zero stress components in the shell are the components that are parallel with the middle surface of shell. The warm forming by gas includes the modeling of pieces by the complicated geometry. Thus, the correct and exact definition of surface in the complicated mould and also the high quality finite element mesh across it is required. Often, the surfaces of mould are irregular morphologically.

The mechanic properties of AA5083 (based on the temperature used in simulation) were obtained knowing the the physical and thermal properties ofAA5083 and plotted in Fig.1 [7,10].

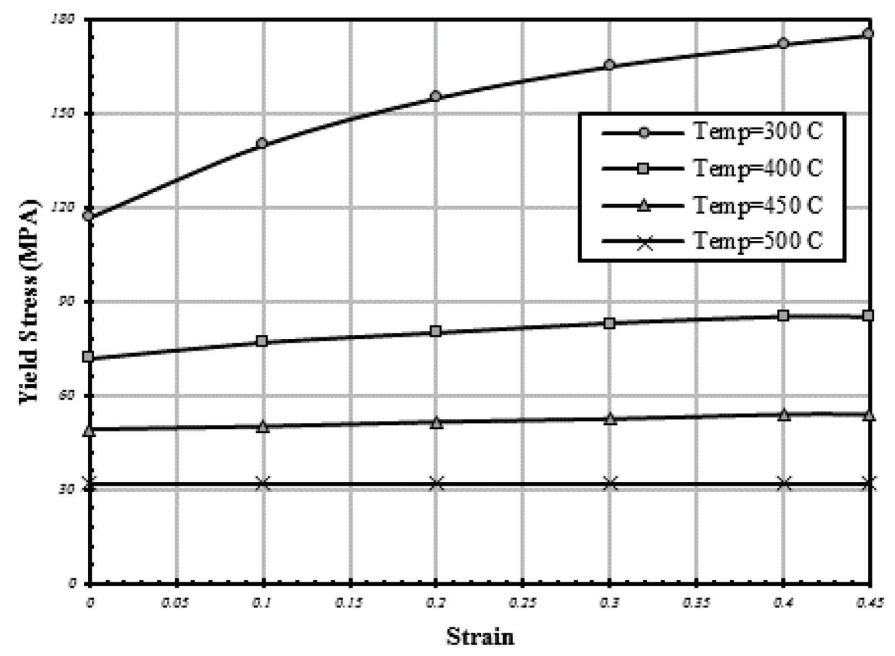

Fig. 1: Diagram of AA5083 stress changes based on temperature [7]

The forming sheet is defined as one deformable piece and the mould is modeled as the analytical rigid pieces. In the software analysis, the opening dimensions of the mould and sheet are in compatible with the conditions of the practical test. The circular sheet 's diameter is $150 \mathrm{~mm}$. the 
external diameter of the mould and the sheet holder is $150 \mathrm{~mm}$ and their internal diameter is $115 \mathrm{~mm}$. Meanwhile, the radius of the opening edge is $5 \mathrm{~mm}$. For the mould and the sheet holder, the Reference Point is determined to apply the mechanic and thermal boundary conditions for the analytical rigid components. Table 1 indicates the loading and thermal conditions.

In order to measure the residual stress in the depth by Central Drilling Method, Strain Gauge installed on the lower plane was applied. Fig. 2 indicates the place of strain gauge schematically. The strain gauge 's data are the average strains across the gage length. Thus, in order to extract the data in the Finite Element Method, the average of node 's data in the strain gauge is applied.
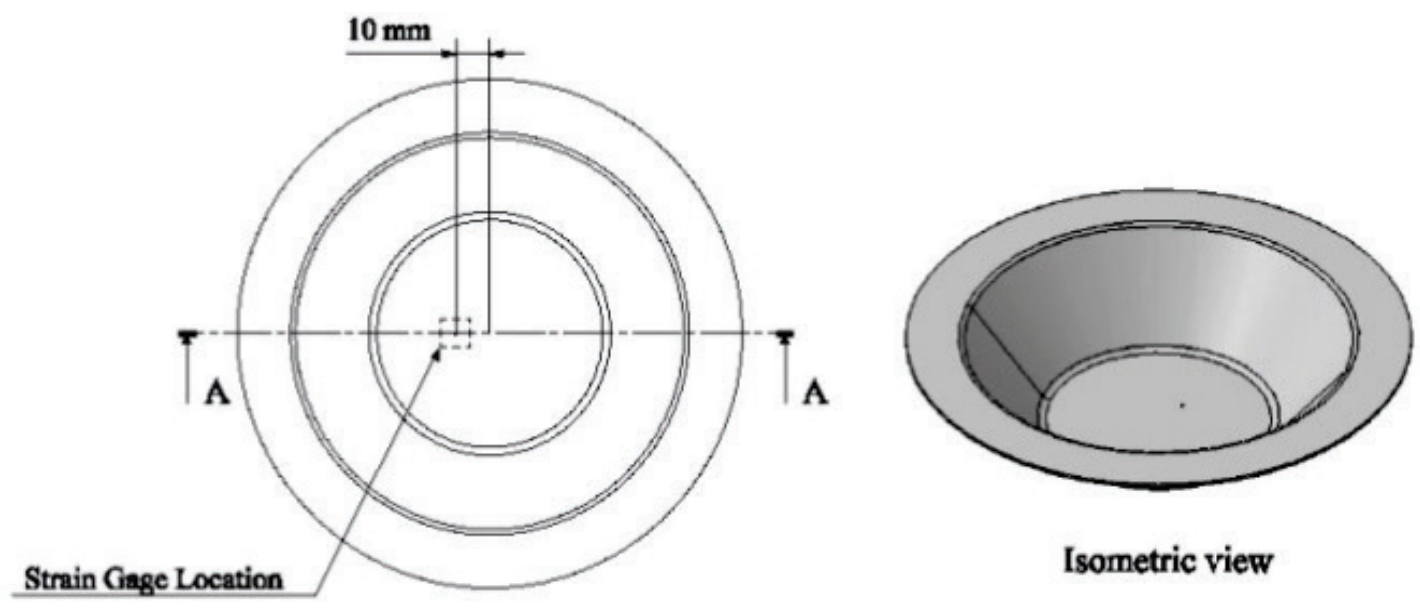

Fig.2: Place of the central drilling in the specimens after forming

\section{Experimental test}

In order to evaluate the inductive residual stress practically in the hot forming process by gas blow, the Central Drilling Method was used (according to ASTM E-837-92).

In this method, the drilling process by the hand drill was used to release the residual stresses caused by the hot metal forming by gas.

Table 1: Warm forming conditions in the tested speciments

\begin{tabular}{llc}
\hline $\begin{array}{l}\text { Forming } \\
\text { Temperature } \\
\text { (ㅇ) })\end{array}$ & $\begin{array}{l}\text { Forming } \\
\text { Pressure } \\
\text { (bar) }\end{array}$ & $\begin{array}{l}\text { Forming } \\
\text { Time (s) }\end{array}$ \\
\hline \multicolumn{1}{c}{500} & 5 & 10 \\
\hline
\end{tabular}

First, the place of the hole was marked and then the place of drill was adjusted on the intended point by the universal tripod tool. Fig. 3 indicates the tripod tool and the drill mounted on the work piece(according to ASTM E-837-92). 

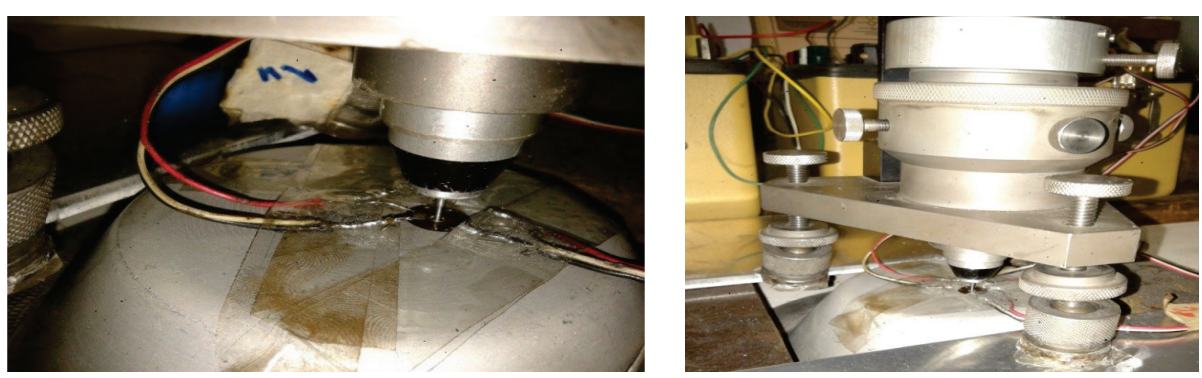

Fig.3: Preparation of piece to measure the residual stress

\section{Simulation and experimental results of tested specimen}

The results extracted by ABAQUS software include the distribution of displacement and stress caused by the simulation of warm metal forming. Figures 4, 5 indicate the sheet 's displacement and the contour of basic stresses of the sheet under the forming process respectively.

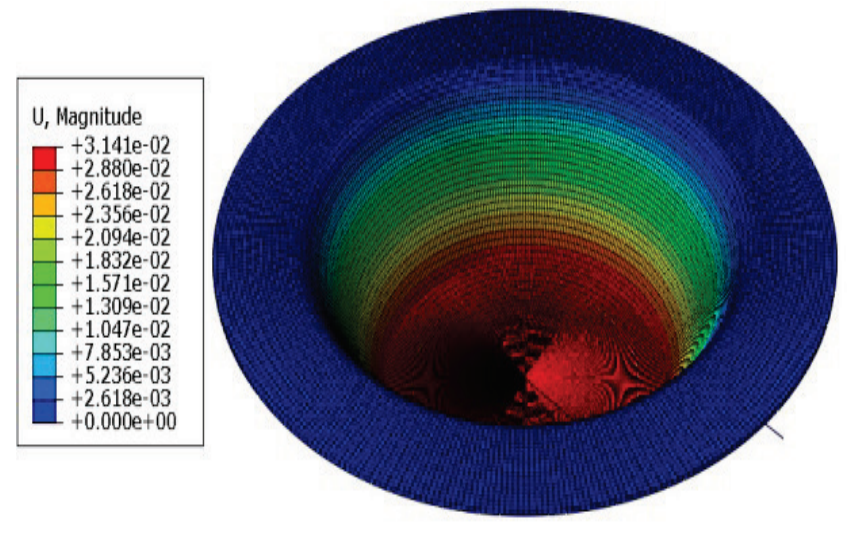

(a)Displacement contour

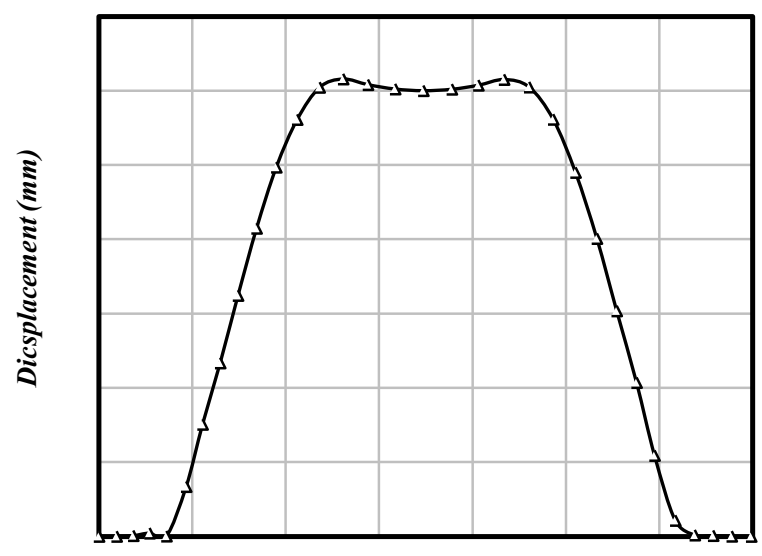

Central Path of Specimen

(b) Displacement plot

Fig.4: sheet's displacement under the warm forming process
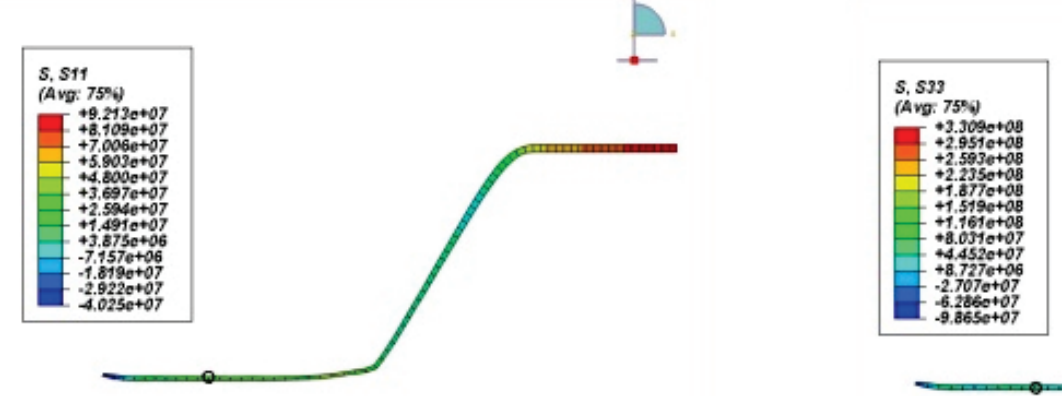

Fig.5: Contour of principal stresses ( $\mathrm{Pa})$ 
In the experimental test, after making the hole, the released strain was recorded for every removed layer (fig.6). With regard to the strains obtained by the experimental test, the residual stress in the piece (equations (2) - (4) in ASTM-E837-92 Standard) was computed.

$$
\begin{aligned}
& \begin{array}{l}
\sigma_{\min }, \sigma_{\max } \\
=\frac{\varepsilon_{3}+\varepsilon_{1}}{4 \overline{\mathrm{A}}} \\
\pm \frac{\sqrt{\left(\varepsilon_{3}-\varepsilon_{1}\right)^{2}+\left(\varepsilon_{3}+\varepsilon_{1}-2 \varepsilon_{2}\right)^{2}}}{4 \overline{\mathrm{B}}} \\
\bar{A}=-\frac{1+v}{2 E} \times \bar{a} \\
\bar{B}=-\frac{1}{2 E} \times \bar{b}
\end{array}
\end{aligned}
$$

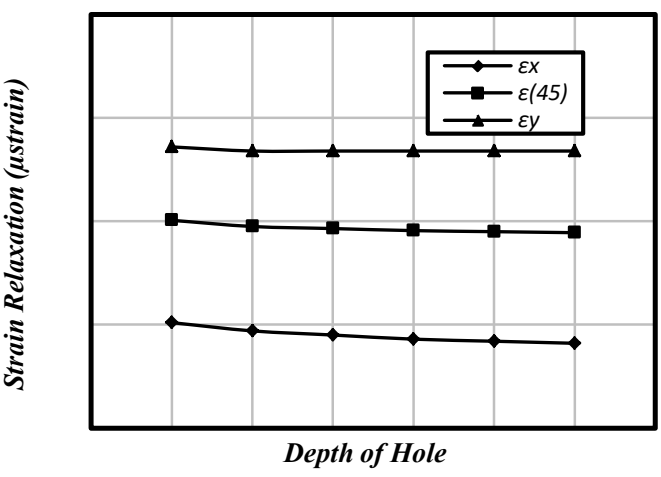

Fig.6: Results of the released strain in the experimental test

\section{Comparison of experimental \& numerical simulation results}

Due to the innate and computational errors in the measuring methods of the residual stress (central drilling) and also the errors of finite element method, it isn't possible to predict the exact value of the residual stress. In this section, the results of tests were evaluated and compared. In fig.7, the stress values obtained by the Finite Element Method and the experimental test were compared.

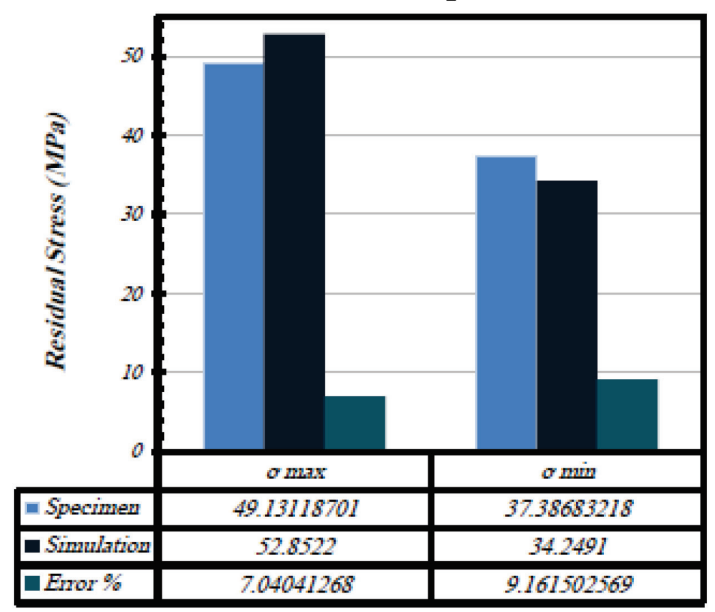

Fig.7: Comparison of residual stress by the simulation and experimental test

As shown in Fig.7, the maximum error in the finite element computations and the experimental test for the maximum stress in the work piece is $7 \%$. In this figure, a very good conformity is seen between these two measuring method. Center hole drilling is measuring method the other is computaional.

Hambli et al [11] studied on the optimization of pressure algorithm in sheet hot forming method by gas blow. They reported their numerical and experimental results about the maximum height of cone with the standard deviation $12 \%$.

The following reasons can be considered as the error source in the measuring method of residual stress by the central drilling. 
1. In this method, the released strains are low that is one of the main error resources in the Central Drilling Method.

2. Making the hole causes the stress concentration on the gauge.

3. The computations of Central Drilling Method based on the plane stress.

4. Error in the strain reading.

\section{Summary \& conclusion}

In the present study, the inductive stresses in the new method of hot metal forming via the aluminum alloy by the gas blow was evaluated by the practical test and the finite element analysis. The finite element analysis of hot metal forming by gas in the Abaqus software indicates that there is a reasonable compatibility between the results obtained by the experimental test and the finite element analysis based on the conditions of experimental test. Also, the results of finite element simulation can be used as a reliable method for the conceivability evaluations, determination of conditions and effective parameters of the process.

\section{References}

[1] S.Toros,F.Ozturk and I.Kacar, "Review of Warm Forming of Aluminum-Magnesium Alloys", Journal of Materials Processing Technology, 207 (1-3), Oct.2008, pp. 1-1. http://dx.doi.org/10.1016/j.jmatprotec.2008.03.057

[2]F.Shehata,M.J.Painter, andR.Pearce, "Warm Forming of Aluminum/Magnesium Alloy Sheet”, Journal of Mechanical Work Technology, 2 (3), Dec.1978, pp. 279-291. http://dx.doi.org/10.1016/0378-3804(78)90023-2

[3]D.Sorgente,L. Tricarico, "Pressure Profile Designing in Superplastic Forming Based on the Strain Rate and on Post-forming Properties", Journal of Materials Engineering and Performance, Vol 23, 2014,pp. 2025-2033. http://dx.doi.org/10.1007/s11665-014-1027-3

[4]J.Roesler,H. Harders and M.Baeker, "Mechanical behavior of engineering materials", Springer, New York,2007.

[5]D.Wilson, "Aluminum versus Steel in the Family Car-the Formability Factor", Journal of Mechanical Work Technology, 16 (3), June.1988, pp. 257-277. http://dx.doi.org/10.1016/03783804(88)90055-1

[6]Tang, J.S., Fuh, Y.K., Lee, S., 2014, "Superplastic forming process applied to aero-industrial strakelet:"wrinkling, thickness, and microstructure analysis", Journal of Advance Manufacturing Technology,

[7]H.Yu Wu, T. M.Da, "Modified male die rapid gas blow forming of fine-grained Mg alloy AZ31B thin sheet", Journal of Advance Manufacturing Technology,2015.

[8] M.Bakhshi-Jooybari, A.Gorji, and M.Elyasi, "Developments in sheet hydroforming for complex industrial parts",Metal Forming,Vol 3,2012, pp. 55-84. http://dx.doi.org/10.5772/48142

[9] A.H.Van Den Boogaard, J.Hu 'etink, "Modelling of aluminium sheet forming at elevated temperatures", Materials Processing and Design: Modeling, Simulation and Applications, Proceedings of the 8th International Conference on Numerical Methods in Industrial Forming Processes, NUMIFORM,2004.

[10] P.F.Bariani, "Hot Stamping of AA5083 Aluminum Alloy Sheets", Journal of Manufacturing Technology, 62 (1), April 2013, pp. 251-254.

[11] R.Hambli, A. Potiron, F.Guerin and B. Dumon, "Numerical Pressure Prediction Algorithm of Superplastic Forming Procedd Using 2D and 3D Modles", Journal of Materials Processing Technology, 112, October, 2001, pp. 83-90. http://dx.doi.org/10.1016/S0924-0136(01)00549-0 